\title{
Interobserver reproducibility of fully quantitative pixel-wise analysis of clinical CMR perfusion imaging
} Hannah Conn*, Li-Yueh Hsu, Susanne Winkler, Allison D Ta, Kim-Lien Nguyen, Peter Kellman, Sujata M Shanbhag,
Marcus Y Chen, W Patricia Bandettini, Andrew E Arai

From 17th Annual SCMR Scientific Sessions

New Orleans, LA, USA. 16-19 January 2014

\section{Background}

Quantitative first pass cardiac magnetic resonance (CMR) perfusion imaging has shown excellent interobserver agreement at a sector level in healthy volunteers and patients. In this study, we compare the myocardial blood flow (MBF) estimates in sector-wise and pixel-wise analysis. We also study the interobserver variability in pixel-wise MBF estimates from patients with coronary artery disease (CAD).

\section{Methods}

First pass CMR imaging was performed on 29 patients with known or suspected CAD ( 15 females, age $54.9 \pm$
14.3 years). Twenty of the patients, defined as the normal group, had minimal or no stenosis ( $<30 \%$ by computed tomographic angiogram) and nine patients, defined as the CAD group, had significant CAD ( $>70 \%$ stenosis by invasive coronary angiography). All patients were scanned on a $1.5 \mathrm{~T}$ scanner using a steady state free precession imaging sequence for regadenoson stress perfusion followed by rest perfusion 20 minutes later. Two observers independently traced the myocardial regions of interest in the midventricular slice and quantified the MBF in sector-wise and pixel-wise analyses by a model-constrained deconvolution approach. Pixel-wise MBF estimates were averaged to six transmural sectors to compare with sector-wise

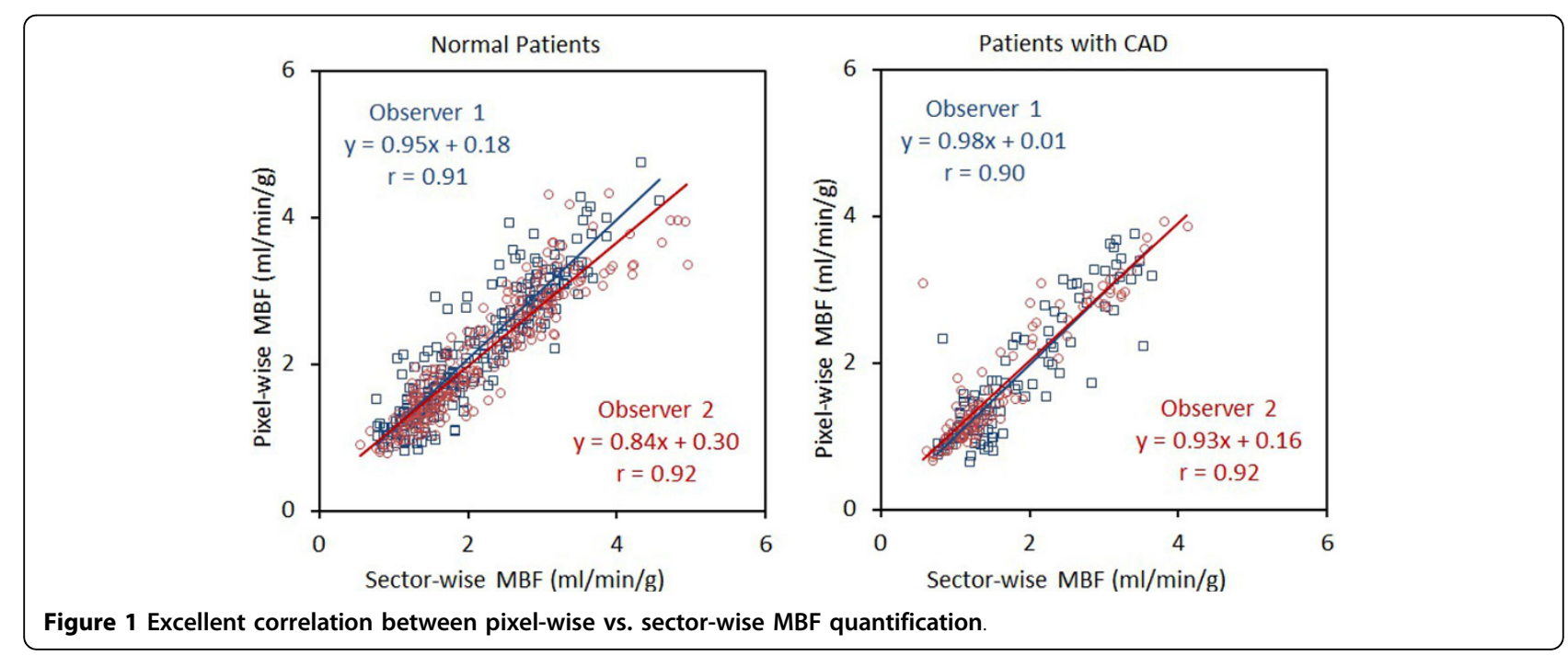

National Heart, Lung, and Blood Institute, National Institutes of Health,

Bethesda, Maryland, USA 

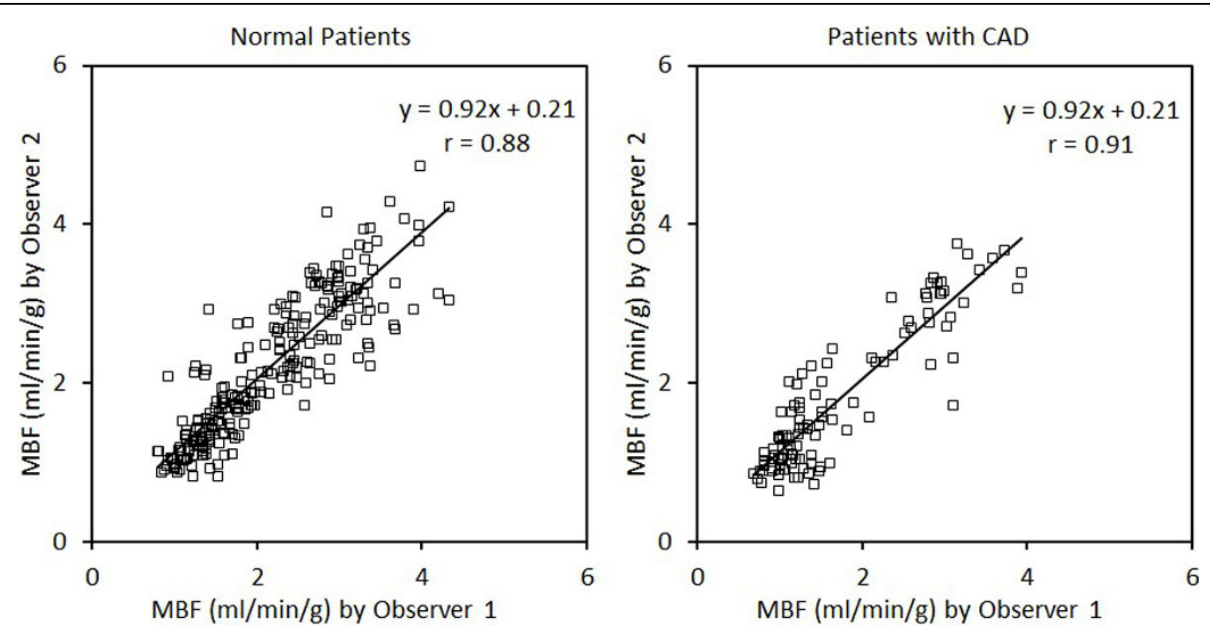

Figure 2 Excellent agreement of pixel-wise MBF quantification between two independent observers.

analysis. Pearson correlation, Bland-Altman analysis, and paired student $\mathrm{t}$-test were used to compare the results.

\section{Results}

There was excellent correlation between pixel-wise vs. sector-wise MBF quantification for the 20 normal and nine CAD patients (Figure 1). In both patient groups, Bland-Altman analysis showed no significant bias between the two methods of quantification (mean bias from 0.01 to $0.12 \mathrm{ml} / \mathrm{min} / \mathrm{g}$ ). Limits of agreement were good (2SD range from 0.26 to $0.98 \mathrm{ml} / \mathrm{min} / \mathrm{g}, \mathrm{p}=\mathrm{NS}$ for all comparison). Interobserver agreement of pixelwise MBF was excellent for both normal and CAD groups (Figure 2). The interobserver agreement was good (2SD range from 0.38 to $0.96 \mathrm{ml} / \mathrm{min} / \mathrm{g}, \mathrm{p}=\mathrm{NS}$ for all comparisons) with no significant interobserver bias (mean bias from 0.02 to $0.15 \mathrm{ml} / \mathrm{min} / \mathrm{g}$ ). The stress $\mathrm{MBF}$ in the ischemic zone of patients with $>70 \%$ stenosis was $1.72 \pm 0.75 \mathrm{ml} / \mathrm{min} / \mathrm{g}$ by pixel-wise analysis which was significantly lower than remote MBF $(2.85 \pm$ $0.74 \mathrm{ml} / \mathrm{min} / \mathrm{g}, \mathrm{p}<0.001$ ).

\section{Conclusions}

Clinical first pass CMR perfusion can be quantified at the pixel level and the results agree well with sector-wise comparison. There is an excellent interobserver agreement in pixel-wise quantification of patients with CAD.

\section{Funding}

This research was supported by the Intramural Research Program of the National Heart, Lung, and Blood Institute, National Institutes of Health.

Published: 16 January 2014
doi:10.1186/1532-429X-16-S1-P350

Cite this article as: Conn et al:: Interobserver reproducibility of fully quantitative pixel-wise analysis of clinical CMR perfusion imaging. Journal of Cardiovascular Magnetic Resonance 2014 16(Suppl 1):P350.
Submit your next manuscript to BioMed Central and take full advantage of:

- Convenient online submission

- Thorough peer review

- No space constraints or color figure charges

- Immediate publication on acceptance

- Inclusion in PubMed, CAS, Scopus and Google Scholar

- Research which is freely available for redistribution

Submit your manuscript at www.biomedcentral.com/submit 